\title{
ORAL MAXILLOFACIAL FRACTURES SEEN AT A UGANDAN TERTIARY HOSPITAL: A SIX-MONTH PROSPECTIVE STUDY
}

\author{
Adriane Kamulegeya, Francis Lakor, Kate Kabenge
}

doi: 10.1590/S1807-59322009000900004

\begin{abstract}
Kamulegeya A, Lakor F, Kabenge K. Oral maxillofacial fractures seen at a ugandan tertiary hospital: a six-month prospective study. Clinics. 2009;64(9):843-8.
\end{abstract}

AIM: To investigate the epidemiological characteristics of maxillofacial fractures and associated fractures in patients seen in the Oral Surgery Unit of Mulago Hospital, Kampala, Uganda.

METHODOLOGY: A six-month prospective study was conducted. Data collected included socio-demographic factors, type and etiology of injury, additional fractures, and post-surgery complications.

RESULTS: One hundred thirty-two (132) cases ranging from 5-70 yrs of age were reported, with a male: female ratio of 7.7:1. The 21-30 yr age group was the largest, comprising $51.51 \%$ of cases ( $n=68)$. Road traffic accidents contributed to $56.06 \%$ ( $\mathrm{n}=74$ ) of fractures. In total, $66 \%$ of the sample $(n=87)$ suffered isolated mandibular fractures. Symphyseal and maxillary fractures were the most common mandibular and mid-facial fractures, respectively. Among associated fractures, the femur was most affected. A total of $39(29.54 \%)$ of patients had post-operative complications, of which infection accounted for $48.71 \%(\mathrm{n}=19)$, and malocclusion accounted for $17.94 \%(n=7)$.

CONCLUSIONS: Anticipated changes in maxillofacial trauma trends necessitate regular epidemiologic studies of facial fractures to allow for development and implementation of timely novel preventive measures.

KEYWORDS: Trauma; Facial injuries; Maxillofacial fractures.

\section{INTRODUCTION}

Maxillofacial fractures are more prevalent in large cities due to heavy traffic and high incidence of violence. The causes, types, and sites of these fractures seem to vary across geographical location. Different studies have shown a relationship between maxillofacial fractures, defined sex and age groups, level of mechanization and development. ${ }^{1-4}$ As man evolved and developed more machinery to ease day to day living, the incidence and severity of trauma injuries to the face also increased. Maxillofacial injuries are rarely fatal but subject the affected individual to tremendous physical and psychological anguish. Although maxillofacial injuries

Oral Maxillofacial Unit of the Department of Dentistry, Mulago Hospital, Complex Mulago Hill - Kampala, Uganda.

Email: adrianek55@yahoo.com

Tel: 256712072432

Received for publication on April 14, 2009

Accepted for publication on June 24, 2009 rarely cause death, they may cause airway compromise and excessive bleeding leading to death. Additionally facial trauma is associated with the cranio-cerebral injury in $20 \%$ of the casualties, another potential cause of death. Worldwide differences in the distribution and occurrence of maxillofacial fractures are said to be a result of differing socio-economic, cultural and environmental influences. ${ }^{5}$ More than $90 \%$ of the world's deaths from injuries occur in low and middle-income countries. ${ }^{6}$ In the last couple of years, Uganda has undergone steady economic and social transformation, seeing increased traffic and population plus competition for resources in urban as well as rural areas. ${ }^{7}$ These factors have most likely led to changes in the patterns and severity of maxillofacial fractures and their causes.

The study was conducted at Mulago hospital, the biggest referral hospital in the country; due to lack of well-manned public health care facilities, this hospital also serves as a primary health care facility. Thus, the patients seen are reflective of the pattern of oral and maxillofacial fractures 
within the greater part of the capital city of Uganda. Our search did not find any recent studies on maxillofacial fractures in Uganda; hence, we aimed to collect information regarding the epidemiology of oral and maxillofacial fractures (excluding teeth). The study also aimed to determine the associated fractures in patients seen at the Oral Maxillofacial Unit of Mulago Hospital.

Our objective was to review the maxillofacial fractures treated in Mulago over a period of six months prospectively from August 2008 to February 2009.

The data was obtained by assessing patients as they presented in the clinic and on the unit ward. Patterns of maxillofacial fractures, concomitant fractures, loss of consciousness, helmets/seat belt use in case of road traffic accidents and assessment of the extent of postoperative complications were recorded at the time of each visit.

\section{METHODOLOGY}

A descriptive prospective study was conducted to investigate the epidemiological characteristics of maxillofacial and associated fractures in patients treated and or admitted at the oral maxillofacial unit of Mulago hospital. Patients treated at the unit over a period of six months, i.e., 1st August 2008 to $28^{\text {th }}$ February 2009, were assessed. Data collection was limited to this six-month period due to the time demands placed on the researchers; at least one researcher had to be present each day of the week to ensure that patients were selected and entered into the study.

Information relevant to the study was obtained from the patient directly; when this was not possible, collateral history was obtained from either the police (who usually bring accident and mob justice cases to the hospital) or relatives attending to the patients. Ethical approval from the hospital ethics committee and written permission from the head of the unit were obtained.

A questionnaire was designed to enable collection of relevant data based on the above objectives. The causes of injury were classified as road traffic accidents (RTAs), falls, assault, occupational, and sports.

The road traffic accidents were further subdivided according to the role of the patient (i.e., driver, rider, passenger or pedestrian) and the type of vehicle (car, motorbike or bicycle). Vehicle and motorbike patients were asked if they had seatbelts or helmets, respectively.

The anatomic locations of mandibular fractures were classified according to Ivy and Curtis, ${ }^{8}$ while zygomatic complex fractures were classified as fractures of the arch, body of the zygomatic bone and comminuted fractures. Maxillary fractures were classified as Lefort I, II, and III. ${ }^{9}$ Maxillofacial fractures were evaluated and the diagnosis was agreed upon by all authors using both clinical and radiographic presentation to asses fracture position. Associated fractures were recorded as assessed and confirmed by their different specialties.

The data was entered into MS Office Excel 2007 and subjected to statistical analysis using SPSS Version 15.

The associations between age, sex, type and cause of fractures were assessed for statistical significance using Chi-square tests. The level of significance $(\mathrm{P})$ was set at $5 \%$.

\section{RESULTS}

A total of 132 patients with 219 oral-maxillofacial fractures were treated at the unit, giving an average of 1.66 maxillofacial fractures per patient. Only 5\% of patients treated at the unit had received primary care before being referred to the unit. The duration of the hospital stay ranged from one day for simple fractures, which were managed and patients discharged, to as long as three months for those with serious associated neurological complications.

The patients' ages ranged from 5-70 years, with a mean age of $28.32(\mathrm{SD}=10.76)$. Of the sample, $117(88.7 \%)$ were males giving a male to female ratio of 7.7:1.

Overall, the 21-30 year age group was the most affected, comprising 68 (or 53\%) of patients. This age group was the most affected among both female and males, as shown in Table 1 ( $\mathrm{P}$ value $<0.05)$.

Table 1 - Age and sex distribution of patients with maxillofacial fractures

\begin{tabular}{lccc}
\hline Age group & \multicolumn{2}{c}{ Sex } & Total $(\mathrm{n}=132)$ \\
\cline { 2 - 3 } & $\begin{array}{c}\text { Male } \mathrm{n}=117 \\
(88.6 \%)\end{array}$ & $\begin{array}{c}\text { Female } \mathrm{n}=15 \\
(11.4 \%)\end{array}$ \\
\hline $1-10$ yrs & $1(0.75)$ & $4(3.03)$ & $5(3.8)$ \\
$11-20$ & $20(15.15)$ & $3(2.27)$ & $23(17.42)$ \\
$21-30$ & $61(46.21)$ & $7(5.30)$ & $68(51.51)$ \\
$31-40$ & $20(15.15)$ & $1(0.75)$ & $21(15.90)$ \\
$41-50$ & $10(7.57)$ & 0 & $10(7.57)$ \\
$51-60$ & $3(2.27)$ & 0 & $3(2.27)$ \\
$61-70$ & $2(1.51)$ & 0 & $2(1.51)$ \\
\hline
\end{tabular}

Road traffic accidents (RTAs) caused $56.06 \%$ of the injuries, followed by assault at $34.84 \%$. Other causes included sports (3.79\%), occupational incidents (3.03\%) and gunshots $(2.27 \%)$. Although the 21-30 age group was most affected, there were no statistically significant relationships between age group and cause of trauma (Tables 2, 3, 4). In total, $90(68.94 \%)$ of patients had isolated mandibular fractures and $27(20.45 \%)$ suffered isolated mid-facial injuries. The distribution of fractures according to cause of injury (Table 5) was found to be statistically significant (Chisquare $=28.27, \mathrm{P}$-value $=0.005, \mathrm{df}=8$ ). 
Table 2 - Distribution of patients according to cause of injury

\begin{tabular}{lccc}
\hline Cause of injury & \multicolumn{2}{c}{ Sex } & Total $(\mathrm{n}=132)$ \\
\cline { 2 - 3 } & Male $\mathrm{n}=117$ & Female $\mathrm{n}=15$ & \\
\hline RTA & $65(49.24)$ & $9(6.81)$ & $74(56.06)$ \\
Assault & $40(30.30)$ & $6(4.54)$ & $46(34.84)$ \\
Sports & $5(3.8)$ & 0 & $5(3.8)$ \\
Occupational & $4(3.03)$ & 0 & $4(3.03)$ \\
Gunshot & $3(2.27)$ & 0 & $3(2.27)$ \\
\hline
\end{tabular}

RTA=Road Traffic Accident

Table 3 - Distribution of patients' age and sex in relation to road traffic accidents

\begin{tabular}{lccc}
\hline Age group & \multicolumn{2}{c}{ Sex } & \multirow{2}{*}{ Total $(\mathrm{n}=74)$} \\
\cline { 2 - 3 } & Male $\mathrm{n}=65$ & Female $\mathrm{n}=9$ & \\
\hline $1-10$ yrs & $1(1.35)$ & $4(5.41)$ & $5(6.76)$ \\
$11-20$ & $12(16.22)$ & $1(1.35)$ & $13(17.57)$ \\
$21-30$ & $32(43.24)$ & $4(5.41)$ & $36(48.65)$ \\
$31-40$ & $11(14.86)$ & 0 & $11(14.86)$ \\
$41-50$ & $6(8.11)$ & 0 & $6(8.11)$ \\
$51-60$ & $2(2.27)$ & 0 & $2(2.27)$ \\
$61-70$ & $1(1.35)$ & 0 & $1(1.35)$ \\
\hline
\end{tabular}

Table 4 - Distribution of patients by age and sex in relation to assault

\begin{tabular}{lccc}
\hline Age group & \multicolumn{2}{c}{ Sex } & Total $(\mathrm{n}=46)$ \\
\cline { 2 - 3 } & Male $\mathrm{n}=40$ & Female $\mathrm{n}=6$ & \\
\hline $1-10$ yrs & $1(2.17)$ & 0 & $1(2.17)$ \\
$11-20$ & $4(8.69)$ & $2(4.35)$ & $6(13.04)$ \\
$21-30$ & $23(50.0)$ & $3(6.52)$ & $26(56.52)$ \\
$31-40$ & $7(15.22)$ & $1(2.17)$ & $8(17.39)$ \\
$41-50$ & $4(8.69)$ & 0 & $4(8.69)$ \\
$51-60$ & 0 & 0 & 0 \\
$61-70$ & $1(2.17)$ & 0 & $1(2.17)$ \\
\hline
\end{tabular}

The most commonly involved mandibular site was the symphysis, which accounted for 26 patients, followed by parasymphyseal fractures at 21 . Both had equal predilection for the right and left sides. In patients with two mandibular fracture lines, a combination of body and angle was the most common pattern at $7.6 \%$, followed by parasymphyseal and angle. There were only two patients with more than two fracture lines. No coronoid fractures were observed.
In the case of the mandible, RTAs were responsible for $48(53.3 \%)$; the symphysis was the most commonly affected site. There was a significant relationship between mandibular fractures and cause of injury (Chi square $=34.26$ P-value $=0.024, \mathrm{df}=20$ ).

In the mid-facial region, $50 \%$ of fractures were due to RTAs. Maxillary fractures were the highest at $30.1 \%$. Mid-facial fractures due to assault were equally distributed between the maxilla and the zygoma. There was no statistically significant relationship between mid-facial fractures and cause of injury (Chi square=33.23 P-value= $0.09, \mathrm{df}=24)$.

Of 132 patients, $22(16.7 \%)$ had concomitant fractures, of which femoral fractures represented $45.45 \%$, followed by ribs and skull with $18.18 \%$ each.

Loss of consciousness was reported in 47 patients (35.6\%) and was associated mainly with RTAs $(72.34 \%$, $\mathrm{n}=34)$.

The major method of management was by mandibulomaxillary inter-fixation, which was used in 119 cases (90.15\%), either with arch bars or eyelet wiring methods. Thirteen cases $(10.85 \%)$ were managed by open reduction and fixation.

Of the 132 patients treated, postoperative complications were observed in 39 patients (30\%). Infection was the most common complication, accounting for 19 cases $(48.71 \%)$, followed by malocclusion in 7 cases $(18 \%)$. All cases of post-treatment infection were managed conservatively using antibiotics, with only two eventually undergoing readmission for debridement followed by internal fixation.

\section{DISCUSSION}

Global differences in the distribution and occurrence of maxillofacial fractures have been seen as a result of socioeconomic, cultural and environmental influences. ${ }^{5}$ Over the last two decades, Uganda has registered impressive economic growth and social transformation resulting in increased motorized transport and other status symbols of the Western life style, especially in the southern part of the country. ${ }^{10}$ However, due to prolonged civil war, the northern

Table 5 - Distribution of maxillofacial fracture patterns according to cause of injury

\begin{tabular}{|c|c|c|c|c|}
\hline \multirow[t]{2}{*}{ Causes } & \multicolumn{3}{|c|}{ Pattern of fractures } & \multirow[t]{2}{*}{ Total $(n=132)$} \\
\hline & Mandible only & Midface only & Mid-face and mandible & \\
\hline$\overline{\mathrm{RTA}}$ & 45 & 17 & 12 & $74(56.06)$ \\
\hline Assault & 37 & 7 & 2 & $46(34.84)$ \\
\hline Sports & 3 & 2 & 0 & $5(3.8)$ \\
\hline Occupational & 3 & 1 & 0 & $4(3.03)$ \\
\hline Gunshot & 0 & 0 & 3 & $3(2.27)$ \\
\hline
\end{tabular}

RTA=Road Traffic Accident 
part of the country has seen less development. Such factors are likely to have had an impact on the distribution and etiology of the maxillofacial trauma injuries seen at health care facilities.

In the present study, the male to female ratio was 7.7:1, which is lower than that reported in Nigeria (16.9:1) and Turkey (25:1), but higher than that of Jordan (1:1) or Canada (3:1). ${ }^{11-14}$ However, the results are similar to those from studies from Kenya (8.4:1) and India (7:1)., ${ }^{2,15}$ The preponderance of male subjects could be attributed to the fact that males are the main earners of the family and work outdoors; therefore, they are more likely to be involved in accidents, violent conduct and sports. ${ }^{5}$ In fact, all of the motorbike riders with maxillofacial fractures in this study (28\%) were male, and $92 \%$ of them rode passenger service motorcycles as their primary occupation. Only two had helmets on at the time of the accident.

The most commonly affected age group was 21-30 years, which is similar to the results of other studies. This is probably due to the greater physical activity and agility seen in this group. ${ }^{11,15}$

In the present study, RTAs constituted the most common cause of injury, similar to studies conducted in India and Iran. ${ }^{15-16}$ In contrast, studies conducted in Finland and Austria $^{17,18}$ found assault and daily activities to be the leading causes of maxillofacial trauma.

RTAs as a cause of morbidity and mortality are on the rise in Uganda. Liberalization in the early 1990s, rapid urbanization and the improving economy have led to a vast increase in motorization. However, improvements in infrastructure have not kept up with the surge in traffic, and as a result, motorbikes have found a niche as a form of public transport. With poor vehicle maintenance, lack of enforcement of traffic rules, low educational status of riders and drivers, inadequate insurance, poor trauma care, outdated legislation and political interference, the problem is likely to get worse. Among the cases of assault, only one female patient reported fracture of the mandible due to domestic violence. All other cases reported assault from thugs as the cause of injury. Although only one female patient acknowledged domestic violence as the cause of her injuries, she insisted that it was the husband's drunken friend who hit her. Studies have reported that women are unwilling to report domestic violence as the cause of their injuries for reasons ranging from cultural to socio-economic ones.${ }^{19}$ Therefore, although we intentionally sought out this information, we may have failed to determine the extent of the role of domestic violence in maxillofacial injuries.

Interestingly, although alcohol is known to be a major factor in maxillofacial injuries, ${ }^{20}$ all our patients denied that alcohol was involved at the time of injury(with the exception of the female patient who reported a drunken husband's friend as the cause of the injury). This was a surprise given the high per capita alcohol consumption reported in the country. ${ }^{21}$ The results are likely not reflective of the actual situation because patients or relatives may not have disclosed despite probing. A more purposeful study to determine the role of alcohol and its influence on fracture patterns and severity should be carried out.

Various studies have confirmed the mandible as the most affected bone in isolated fractures. ${ }^{12,18}$ This preponderance could be due to the fact that the mandible is the most prominent and only moveable facial bone, and hence has a greater chance of being fractured than the well-articulated mid-facial bones. In our study, the symphysis was the most common site, followed closely by the parasymphiseal area. This is in contrast with other published data, which have reported the body ${ }^{12}$ and condyle ${ }^{18}$ as the most frequently affected sites.

Among fractures of the mid-facial region, maxillary factures were the most common, followed by zygomatic body fractures. The maxilla has been reported to be the most common site for mid-facial fractures in many other studies. ${ }^{14,22}$ However, some studies have reported the zygoma as the most common site of mid-facial fractures. ${ }^{23,24}$

Fractures of the body of mandible were the most frequent fractures due to road traffic accidents, whereas the angle was most affected due to assault. This is partly in line with other published studies, which have found the body of the mandible to be the most affected site in RTAs, ${ }^{25}$ and the angle to be the most common site in cases of assault. ${ }^{5}$ No patients reported falls that might be due to climate and living conditions. With no winter or snow, few people living in storied buildings and fewer concretized floors, falls in Uganda generally occur on soft ground, resulting in a decreased likelihood of fractures. The body of the zygoma was the most common fracture site for sports injuries. These results were in agreement with a study conducted in Switzerland. ${ }^{26}$

Facial fractures can occur in combination with other fractures and loss of consciousness, as reported by other studies. ${ }^{14,15,18}$ Hence, immediate diagnosis and interdisciplinary cooperation between general surgeons; orthopedic, plastic, neurosurgical and ophthalmologists and maxillofacial teams is of utmost importance. A total of $35.6 \%$ of the patients in this study had experienced loss of consciousness; $72.34 \%$ of these patients were involved in road traffic accidents (RTAs). This may be due to the fact that $66.21 \%$ of all RTAs were due to motorbike accidents, with the bulk of patients (77.55\%) being the riders. Similar statistics regarding motorbikes dominating road traffic accidents as a cause of facial fractures have been reported in 
Brazil. ${ }^{27}$ In our study, only two riders were wearing helmets at the time of the accident. The failure of both motorbike riders and their passengers to wear helmets is unfortunate because a decrease in facial fractures and skull injuries has been reported when helmets are used. ${ }^{28}$ Although Uganda has a law enforcing the use of helmets for both rider and passenger, such laws are seldom obeyed; hence, a great deal of public sensitization is required to enforce this law. In Uganda, a few attempts have been made to enforce seatbelt and helmet laws, but politics often interferes; therefore, these safety measures are rarely practiced.

The closed method of fracture reduction was employed in $90.15 \%$ of patients in this study, higher than that of other studies such as the $40 \%$ reported by Vetter et $\mathrm{al}^{13}$ and the $35 \%$ reported by Martini et al. ${ }^{27}$ and $70.2 \%$ by Ssentongo ${ }^{29}$. This was mainly due to the cost of open reduction and the lack of plates and theater space to perform the procedure. MMF remained the primary mode of management in all of these studies. Health care in most African and other lowincome countries is still in the hands of the government. Most governments allocate insufficient funds to health care, leaving both rural and urban hospitals heavily resourceconstrained..$^{30}$ As a result, hospitals choose the cheapest mode of management to allow for as many patients to have access to care as is possible within the limited budgetary allocations. MMF and intraosseous wiring are cheap ways to manage maxillofacial fractures and are likely to dominate over plating for the foreseeable future.

In our sample, $30 \%$ of patients suffered from postoperative complications, which is similar to the findings of Devadiga ${ }^{15}$ but higher than the $18 \%$ reported by Hosein. ${ }^{31}$
However, our percentage was lower than the $61.54 \%$ reported by Aboise..$^{32}$ Of the observed complications, infection ranked highest at $48.71 \%$. The high rates of infection in the present study could be ascribed to the use of closed reduction with MMF and its accompanying oral hygiene and nutritional challenges. However, given the cost of dental care relative to the earning capacity of our patients, many of them presented with very poor oral hygiene; we were not able to improve the situation before the MMF was performed. Therefore, the high infection rate was not a surprise.

\section{CONCLUSIONS}

Data on trauma and its complications is important for every country, as it helps in planning and improving facilities as well as in creating laws and public health initiatives that help prevent and/or reduce trauma from traffic-related accidents. Collecting data on trauma also aids in planning with regard to the skills and facilities necessary for handling reports to health care centers. Information obtained on factors such as occupation, alcohol intake, helmet/seatbelt use, and type of RTAs could be useful in enforcing appropriate preventive measures. Development, especially in low-income countries, is likely to manifest changes in the trends and complexities of oral-maxillofacial trauma, necessitating regular epidemiological studies of these fractures and their causes so as to allow for development and implementation of timely novel and appropriate preventive and treatment measures.

\section{REFERENCES}

1. R Voss. The aetiology of jaw fractures in Norwegian patients. $\mathrm{J}$ Maxillofac Surg 1982; 10:146-8.

2. DL Mwaniki, SW Guthua. Occurance and characterisics of mandibular fractures in Nairobi, Kenya. Br J Oral Maxillofac Surg. 1990;28:200-20.

3. Ajagbe HA, Daramola JO. Pattern of facial bone fractures seen at the university college hospital, Ibadan, Nigeria. East Afr Med J. 1980;57:267-73.

4. Güven O. A Comparative Study on Maxillofacial Fractures in Central and Eastern Anatolia. J Craniomaxillofac Surg 1988;16:126-9.

5. Dongas P, Hall GM. Mandibular fracture patterns in Tasmania, ten years of mandibular fractures: An analysis of 2137 Cases. Aust Dent J. 2002;47:131-7.

6. Peden M, Sminkey L. The Injury Chart Book, WHO, Geneva 2000. Special feature world health day 2004-Road Safety. Available at URL: http://www.who.int/violence_injury_prevention/road_traffic/en/ unrs_collab_append.pdf. Accessed on 24/3/2009.
7. Kilimani N. Financial Development and Economic Growth in Uganda. The Icfai Journal of Financial Economics, 2007; Vol. V.(1)14-34.

8. Banks P. Killey's fractures of the mandible, 4th edition: Varghese Publishing House; 1993.

9. Banks P. Killey's fracture of the middle third of the facial skeleton, 3rd ed: Varghese Publishing House; 1993.

10. Uganda. African economic outlook. http://www.oecd.org/ dataoecd/13/3/40578334.pdf. Accessed on 09/4/2009.

11. Adekeye EO. The pattern of fractures of the facial skeleton in Kaduna, Nigeria: A survey of 1,447 cases. J Oral Surg. 1980;49:491-5.

12. Kerim O, Yilmaz G, Sinan AY, Bayar. An analysis of maxillofacial fractures: A 5 yr survey of 157 patients. Military Med. 2004;169:723-7.

13. Vetter JD, Topazian RG, Goldberg MH, Smith DG. Facial fractures Occurring in a Medium Sized Metropolitan Area: Recent Trends. Int J Oral Maxillofac Surg. 1991;20:214-6. 
14. Hogg NJ, Stewart TC, Armstrong JE, Girotti MJ. Epidemiology of Maxillofacial Injuries at Trauma Hospitals in Ontario, Canada, Between 1992 and 1997. J Trauma. 2000;49:425-32.

15. Devadiga A \& Prasad, K. S.V. Epidemiology of maxillofacial fractures and concomitant injuries in a craniofacial unit: A retrospective study. The Internet Journal of Epidemiology. 2008;5:2.

16. Zargar M, Khaji A, Karbakhsh M, Zarei MR. Epidemiology study of Facial Injuries during a 13-month of Trauma Registry in Tehran. Indian J Med Sci. 2004;58:109-14.

17. Kontio R, Suuronen R, Ponkkonen H, Lindqvist C, Laine P. Have the causes of maxillofacial fractures changed over the last 16 years in Finland? An epidemiological study of 725 fractures. Dent Traumatol. 2005;21:14-19.

18. Gassner R, Tuli T, H.achl O, Rudisch A, Ulmer H. Cranio-maxillofacial trauma: a 10 year review of 9543 cases with 21067 Injuries. Journal of Cranio-Maxillofacial Surgery. 2003;31: 51-61.

19. Barriers to Addressing Violence. In population reports. Issues in World Health. (1999) XXVII, 4 Series L 11. URL: http://www.infoforhealth. org/pr/111/111chap6_1.shtml. Accessed on 8/06/2009.

20. Kai H Lee, Leslie Snape. Role of alcohol in maxillofacial fractures. N Z Med J. 2008;121(1271). http://www.nzma.org.nz/ journal/121-1271/2978.

21. http://www.afro.who.int/dnc/databases/substance_abuse/alcohol_ country_profile/Uganda.pdf (Acessed on 08 Jun 2009).

22. Al Ahmed HE, Jaber MA, Abu Fanas SH, Karas M. The pattern of maxillofacial fractures in Sharjah, United Arab Emirates:A review of 230 cases. Oral Surg Oral Med Oral Pathol Oral Radiol Endod 2004;98:16670.
23. Shaikh ZS, Worrall SF. Epidemiology of facial trauma in a sample of patients aged 1-18 years. Injury. 2002:33;669-71.

24. Klenk G, Kovacs A. Etiology and Patterns of Facial Fractures in the United Arab Emirates. J Craniofac Surg. 2003:14;78-84.

25. Ellis E, Moos KF, El-Attar A. Ten years of mandibular fractures: An Analysis of 2137 patients. J Oral Surg. 1985;59:120-9.

26. Exadaktylos AK, Eggensperger NM, Eggli S, Smolka KM, Zimmermann $\mathrm{H}$, Iizuka T. Sports related maxillofacial injuries: the first maxillofacial trauma database in Switzerland. Br J Sports Med. 2004;38:750-3.

27. Martini MZ, Takahashi A, de Oliveira Neto HG, de Carvalho Júnior JP, Curcio R, Shinohara EH. Epidemiology of Mandibular Fractures Treated in a Brazilian Level I Trauma Public Hospital in the City of São Paulo, Brazil. Braz Dent J. 2006;17:243-8.

28. Johnson RM, McCarthy MC, Miller SF, Peoples JB. Craniofacial trauma in injured motorcyclists: the impact of helmet usage. J Trauma. 1995;38:876-8.

29. Ssentongo K. Maxillofacial fractures in Western province Zambia, an 18 months study. Odonto-Stomatologie Tropicale. 1996;22-3.

30. World Health Organization. World health report-NHA annexes. www. who.int/nha/country/whrannex/en (accessed 06 Jun 2009).

31. Hosein M, Motamedi K. An assessment of maxillofacial fractures: A 5-year study of 237 patients. J Oral Maxillofac Surg. 2003;61:61-6.

32. Abiose BO. Maxillofacial skeleton injuries in the western states of Nigeria. Brit J Oral Maxillofac Surg. 1986;24:31-9. 